\title{
Feeling the emotions, finding the resources: a pathway toward balanced parenting?
}

\author{
Alessandro Pepe \\ Universidad de Milano, Biccoca \\ mail: alessandro.pepe1dunimib.it \\ ORCID: https://orcid.org/0000-0001-8860-0702
}

\section{Elisabetta Biffi}

Universidad de Milano, Biccoca

mail: elisabetta.biffidunimib.it

https://orcid.org/0000-0002-1920-2185

\author{
Eleonora Farina \\ Universidad de Milano, Biccoca \\ mail: eleonora.farina1 dunimib.it \\ https://orcid.org/0000-0003-4485-764X
}

\begin{abstract}
The pandemic made childcare a major challenge for parents globally, both in the short and longer term. In this context, it is plausible that emotions and general distress experienced by parents have had an impact at multiple levels in their relationships with their children, potentially increasing their vulnerability. The present study focuses on the analysis of the prevailing emotions of Italian parents during the first lockdown, investigating possible associations with personal perceptions of well-being and readiness to cope with the emergency situation. 319 parents (93\% mothers) answered to a semi-structured computer assisted web interview (CAWI; Kurniawan, 2018). The answers showed that parents went through intense emotions, both negative, like worry and anxiety (39.2\% named only negative emotions and 32\% negative emotions as prevalent) and positive emotions, like hope, serenity and joy (7.8\% indicated only positive emotions and $9.5 \%$ positive emotions as prevalent). Parents' perceived positive emotions have proved to be important resources linked to a higher level of personal well-being and the perception of being adequately equipped to deal with an emergency. Emotion management emerged as a key area affecting the parents' way of relating with their children during the strict lockdown: parents declared their need to be supported in building a positive emotional relationship with their children in a stressful situation, highlighting a difficulty to cope with and communicate their own emotionality.
\end{abstract}

Keywords: lockdown, covid-19, parents' emotion, children wellbeing.

\section{Sentir las emociones, encontrar los recursos: ¿un camino hacia la crianza equilibrada?}

\section{RESUMEN}

La pandemia convirtió el cuidado de los hijos en un gran reto para los padres en todo el mundo, tanto a corto como a largo plazo. En este contexto, es plausible que las emociones y la angustia general experimentadas por los padres hayan tenido un impacto a múltiples niveles en sus relaciones con sus hijos, aumentando potencialmente su vulnerabilidad. El presente estudio se centra en el análisis de las emociones predominantes de los padres italianos durante el primer cierre, investigando las posibles asociaciones con las percepciones personales de bienestar y la preparación para hacer frente a la situación de emergencia. 319 padres (93\% madres) respondieron a una entrevista web semiestructurada asistida por ordenador (CAWI; Kurniawan, 2018). Las respuestas mostraron que los padres pasaron por emociones intensas, tanto negativas, como la preocupación y la ansiedad (el 39,2\% nombró solo emociones negativas y el $32 \%$ emociones negativas como prevalentes) como emocionales positivas, como la esperanza, la serenidad y la alegría (el 7,8\% indicó solo emociones positivas y el 9,5\% emociones positivas como prevalentes). Las emociones positivas percibidas por los padres han demostrado ser recursos importantes vinculados a un mayor nivel de bienestar personal y a la percepción de estar adecuadamente equipados para afrontar una emergencia. La gestión de las emociones surgió como un área clave que afecta a la forma en que los padres se relacionan con sus hijos durante el encierro estricto: los padres declararon su necesidad de ser apoyados en la construcción de una relación emocional positiva con sus hijos en una situación de estrés, destacando una dificultad para hacer frente y comunicar su propia emocionalidad.

Palabras Clave: encierro, covid-19, emoción de los padres, bienestar de los niños.

ISSN: 0210-2773

DOI: https://doi.org/10.17811/rifie.50.4.2021.807-814 


\section{Feeling the emotions, finding the resources: a pathway toward} balanced parenting?

The pandemic made childcare a major challenge for parents globally, both in the short and longer term. In this context, it is plausible that emotions and general distress experienced by parents have had an impact at multiple levels in their relationships with their children, potentially increasing their vulnerability. The present study focuses on the analysis of the prevailing emotions of Italian parents during the first lockdown, investigating possible associations with personal perceptions of well-being and readiness to cope with the emergency situation. 319 parents (93\% mothers) answered to a semi-structured computer assisted web interview (CAWI; Kurniawan, 2018). The answers showed that parents went through intense emotions, both negative, like worry and anxiety (39.2\% named only negative emotions and $32 \%$ negative emotions as prevalent) and positive emotional, like hope, serenity and joy (7.8\% indicated only positive emotions and $9.5 \%$ positive emotions as prevalent). Parents' perceived positive emotions have proved to be important resources linked to a higher level of personal well-being and the perception of being adequately equipped to deal with an emergency. Emotion management emerged as a key area affecting parents' way of relating with their children during the strict lockdown: parents declared their need to be supported in building a positive emotional relationship with their children in a stressing situation, highlighting a difficulty in cope with and communicate their own emotionality.

\section{Between fear and hope: feeling emotions in traumatic situations}

It is well known that restrictions to freedom of movement related to social isolation are among the main conditions that have a negative impact on psychological well-being (Veronese et al., 2017a; Veronese et al., 2017b). From investigations conducted in previous epidemics that were severe even if not as widespread as Covid-19 (e.g., Ebola, SARS, HIV) we know of adverse psychosocial consequences not only for those who contract the disease but also for the population that does not come into direct contact with it (Blakey et al., 2015; Leung et al., 2003). The current health emergency supported data from the literature, showing a general decline in perceived well-being across all age groups (Favieri et al., 2020; Huang, \& Zhao, 2020; Wang et al., 2020).

Research on the emotional impact of the pandemic, which focused on children in particular, traces the data collected in previous situations with magnitude comparable to the current situation: as in the past, research shows a significant increase in symptoms of post-traumatic stress related to the condition of quarantine in children and adolescents (e.g., Di Giorgio et al., 2020; Di Giorgio et al., 2020; Uccella et al., 2021; Sprang \& Silman, 2013): emotional and mood disorders, irritability, difficulty in self-regulation and concentration, sleep, anxiety and somatoform disorders.

As already pointed out in previous studies on the impact of severe disasters or sudden public health events on mental health, children's negative emotions are closely related to the family climate and in particular to the negative emotions in turn experienced and expressed by parents (Sprang \& Silman, 2013; Juth et al., 2015; Cobham et al., 2016). An interesting recent study by Spinelli and colleagues (2020) reported that the most important factor for the onset of emotional and behavioral disturbances in children during the Covid-19 pandemic was the level of stress perceived by parents in managing daily life, which emerged as even more relevant than the levels of incidence of the virus in their area of residence or having had direct experience of the effects of the virus.

This is not surprising, considering that parents are an important part of a child's personal resources, playing a crucial role in building resilience and alleviating any negative consequences of particularly stressful situations on their mental health (Holmes et al., 2020). Moreover, the measures taken to contain the pandemic have for the most part coincided with a significant increase in the amount of time spent together - at least in the same living spaces - between children and parents, with the latter becoming virtually the only people accessible as sources of psychosocial support.

According to the tripartite model of family impact on children's emotional regulation and adjustment proposed by Morris et al. (2007), parents influence children's emotional response to events through three modes: (i) processes of imitation, (ii) the type of response to emotions exhibited by children, and (iii) the general affective environment in which the child is immersed at home. In other words, from this perspective, children tend to imitate the emotional responses they see their parents enact, both in terms of emotional content in correspondence to certain eliciting events/situations, and in the ways in which these emotions are expressed and managed. Moreover, children build up an idea of the value of their own emotions and of the possibility of managing them on the basis of the contingent responses they receive from their parents to their emotional manifestations. Finally, the possibility of talking about emotions and an open and relaxed emotional climate in the family are factors that positively influence children's development of emotional self-regulation skills. As confirmed by several longitudinal studies by Denham, children with more affectively positive and balanced parents are themselves more affectively balanced. In addition, parents who manage to maintain positive affectivity during difficult circumstances have children who are more able to understand and regulate emotions: if parents can be supportive of their children in stressful situations, their children are less likely to be emotionally overloaded and in turn learn to better manage similar events. During the lockdown, the thinning - and in some cases merging - of boundaries between family and work led to a reorganization of daily life, accompanied, as noted above, by increased levels of stress, anxiety, and other negative emotions (Pfefferbaum \& North, 2020; Restubog et al., 2020). Recent research by Rothe and colleagues (2021) shows significantly higher levels of perceived stress among adults who have children, compared to adults without children.

On the basis of what has been stated so far, it is plausible that the emotions of fear, worry, and general distress experienced by parents have had an impact at multiple levels in their relationships with their children: these negative emotions may resonate in children through mechanisms of "affective induction" described by Denham et al. (1997). Moreover, observation of the ways in which their parents coped and reacted in the face of difficulties was an important indicator for children to modulate their own thoughts and emotions in the face of the pandemic. Finally, states of anxiety and worry may have interfered with parenting practices that, in turn, play an important role in regulating children's behavior and emotions (Masten and Coatsworth, 1998). Indeed, as Spinelli and colleagues (2020) hypothesize in commenting on the results of their study of family well-being during lockdown, under conditions of high stress and worry, parents are more likely to respond inadequately to their children's needs and have difficulties in managing discipline.

For these reasons, attention to parental reactions and emotions can be especially helpful in identifying children and adolescents at increased risk for psychological distress as a consequence 
of the pandemic crisis. But it is fair to wonder what parents' perceptions were with respect to their emotional experiences. As is easy to think and already partly anticipated, research speaks of anxiety and worry as prevalent emotions, perceived to a higher degree by women, people with poor health conditions and the elderly (Barari et al., 2020; Cavioni et al., 2021). However, from surveys conducted on the texts of messages posted on social media, we also know that emotions, during this pandemic, have been and still are - many and diverse, sometimes conflicting. The monitoring of Italians' emotions conducted by Sociometrica starting from the first weeks of March 2020 shows interesting evolutions in the distribution of terms referring to emotions and emotional expressions: at the beginning of the pandemic, fear is in first place, flanked by words belonging to the semantic area of calm/ quietness; then there is sadness, anxiety, hate, but also empathy; as the weeks go by, the words "trust" and "optimism" emerge to a greater extent, sometimes even surpassing fear. These data return the image of a sort of emotional swing that has characterized this difficult period, but which is also indicative both of a progressive understanding of the seriousness and the many implications of this situation, and of a continuous adaptation and re-adaptation to the conditions linked to the evolution of the pandemic.

In this scenario, the present contribution focuses on the analysis of the prevailing emotions felt by Italian parents during the first lockdown, investigating their associations with personal perceptions of well-being and readiness/equipment to cope with the emergency situation. The results of the present research were discussed in terms of support to parenthood and education of parents in time of emergency.

\section{The study}

\section{Sample}

A sample of 319 respondents was used in the present study. The majority of them were mothers (93\%) of a two-parents' family $(80.9 \%)$. Parents' age ranged from 29 to $57(\mathrm{M}=41.9$, SD $=6.04$ ). Mean number of children was 1.9 , with children ages ranging from 3 months to 18 years. With regards to educational level, 57\% reported an university (or more) degree whereas $4.9 \%$ a lower secondary degree. Almost all participants $(91.1 \%)$ were in Lombardy during the COVID-19 emergency. We adopted a snowball convenience sample (Emerson, 2015), all parents of underage $(<18)$ children living in Italy during the COVID-19 outbreak were eligible. Criteria for being included were: (1) Having children living at home less than $18,(2)$ having spent at least 4 weeks locked down at home, (3) experiencing the lockdown in Italy. Excluding criteria were not set. Date were collected for a period of two weeks, starting from April 14 to end on April 28. The strict "lockdown" period in Italy began March, 14 and would then end in early June 2020.

\section{Procedure and materials}

The study was an exploratory parallel mixed-method research (Teddlie, \& Tashakkori, 2006) using, as a primary source of information, a multi-method, parent centered, semi-structured computer assisted web interview (CAWI; Kurniawan, 2018). The interview consisted of four main sections: (1) demographic background, (2) changes in daily routines and personal spaces, (3) parental practices in time of COVID-19 and (4) psychological and emotional consequences of living in lockdown during a pandemic outbreak. In each section both closed ended questions (e.g. Likert type response scales and visual analog scales) and open-ended question were included with the rationale of triangulate emerging data and cross-validate results (Denzin, 2012). Qualitative data gathered from the interviews were analyzed by mean of content analysis (CA;Hsieh, \& Shannon, 2005). In the present paper CA was applied by counting all words referring to emotions and then emotions were categorized in positive, negative, predominantly positive, predominantly negative. Data were collected anonymously, and all participants were informed about the contents of the research. Participation to the study was a voluntary base meaning that any monetary or financial rewards was offered to the participants. The study was approved by the Ethical Board of the Milano-Bicocca University (prot. N. 0034537/20) and it was conducted according to the ethical principles defined by the Declaration of Helsinki (World Medical Association, 2001) and the American Psychological Association code of conduct (American Psychological Association, 2010). The research protocol was part of an ERASMUS+ program (DepCip 2019-1-TR01-KA204-077577) devoted to the education for parents for children protection.

\section{Results \\ What I feel and how I see myself: parents during the first lock- down}

When you think about your emotions, what are the three emotions that most identify your current state of mind? This is not a simple request to "make a list": implicitly, parents were asked to stop and listen to their own states of mind at a difficult - or at least new - time for everyone.

The parents' words seem to confirm that the request, apparently simple in its formulation, implied a greater complexity. In many cases, the words chosen do not indicate real emotions, but physiological states (e.g. tiredness) or temperamental characteristics (e.g. patience). This may indicate a lack of habit or difficulty in some parents to question themselves about their internal states, distinguishing what may be a physiological manifestation from the emotional state connected to it. It may also be a datum linked to the emotional disorientation emerged in the literature and confirmed by some answers in which mothers do not limit themselves to indicating emotional terms, but express their feelings in a more complex way:

\section{"I alternate between states of serenity and slight anxiety. I feel suspended in a particular time" \\ "I often swing between very different states of mind".}

From a psychological point of view, these expressions seem to reflect the sense of bewilderment in the face of the continuous demands of adaptation and re-adaptation linked to the poor predictability associated with the contagion and the lack of knowledge about the virus, especially in the initial phases. Moreover, considering other aspects of the situation, such as the reduction of individual planning and social isolation, it is understandable how the measures to protect one's own health can potentially generate opposite experiences: security and perception of control of the situation, but also anger and frustration.

Observing the frequency of terms referring to emotional states indicated by the participants in our research (Figure 1), the picture is characterized, as expected, by emotions that can be defined as "negative" such as worry, anxiety and fear, in the first three places. However, they are immediately followed by the group of terms related to the semantic sphere of calm, tranquility and - not far away - we can also find words such as joy and happiness, with a frequency equal to that of anger and uncertainty. 


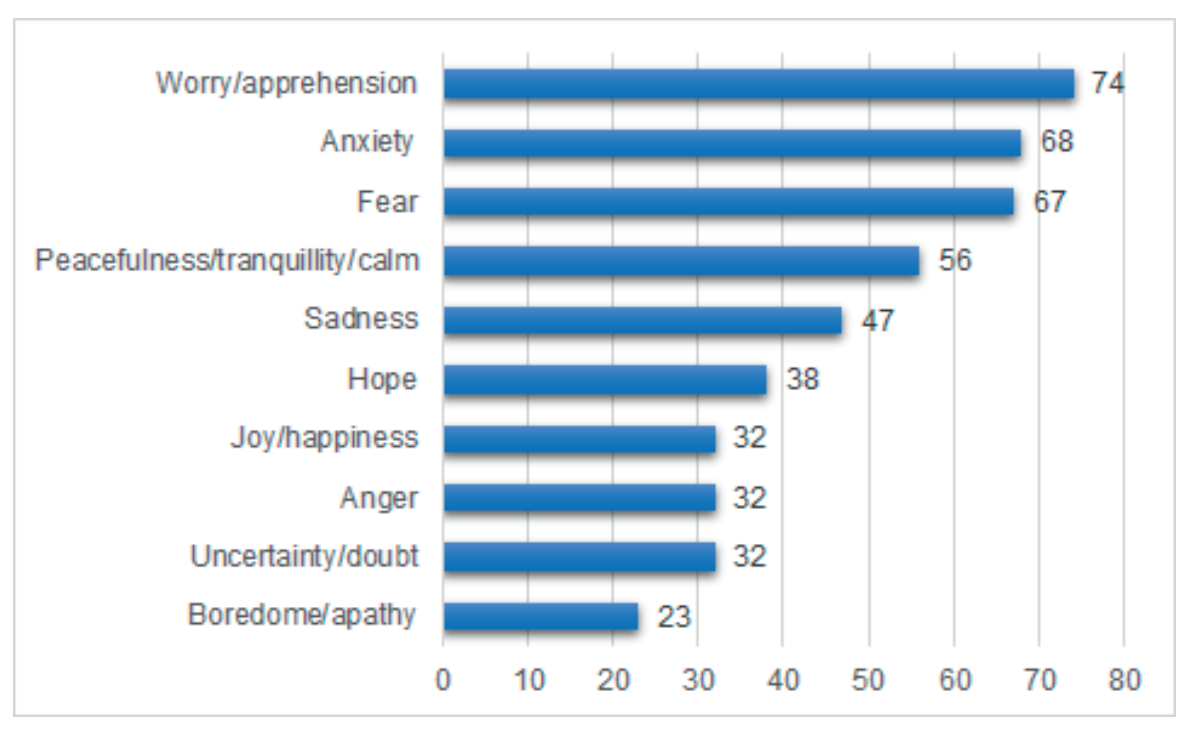

Figure 1. Terms referring to emotional states indicated by parents (the ten most frequently)

At a first glance, therefore, it is already possible to identify the important presence of an underlying worry, which in some cases becomes fear and in others leads to states of anxiety; however, this does not seem to be an obstacle to the identification of potential aspects that arouse positive moods. Analyzing more deeply, within the answers of each participant, the proportion between positive and negative moods, we observe that $39.2 \%$ of the participants choose to indicate only negative emotions and another $32 \%$ out of three emotions, indicate two negative ones but also a positive one. There is also $9.5 \%$ of parents who indicate predominantly positive emotions and $7.8 \%$ name only positive emotions. Obviously, there are many aspects to be considered in relation to the experiences reported by parents: first and foremost, the "external" conditions, such as available space, the possibility or not of continuing to work and under what conditions, having come into contact with the virus, etc. Along with these factors, however, are to be considered more personal aspects, related to the ability to cope with stressful events, which includes a number of strategies, variously classified by different authors. Among them, Lazarus and Folkman (1984) identify adaptive coping strategies centered on emotions, that is, introspective ways of focusing on one's own emotional experience and of reinterpreting a problematic situation in order to give it more meanings, including positive ones, which in turn favor the emergence of positive emotional states.
We can therefore reasonably assume that the perception of positive and/or negative emotional states is the result of the interaction between environmental, inter-individual and intra-individual factors. But what connection might there be between what parents feel emotionally and how they feel? In the following, we will attempt to explore the relationships between emotions and perceptions of personal well-being and self-efficacy/ readiness to cope with the emergency.

\section{Emotion and wellbeing}

A further section of the questionnaire provided for the investigation of personal well-being detected through the use of the WHO-5 instrument - World Health Organization Wellbeing Index (World Health Organization, 1998): parents indicated the frequency of some moods and physiological states perceived in the last two weeks. From these responses it was possible to obtain a cumulative score on a 100 basis that allows the evaluation of the level of individual well-being perceived. The average well-being of the group of parents who participated in the research is 55, 9,: just above the median, but what is more interesting is the analysis of the levels of perceived well-being in relation to the identification of more or less positive emotions during the lockdown period.

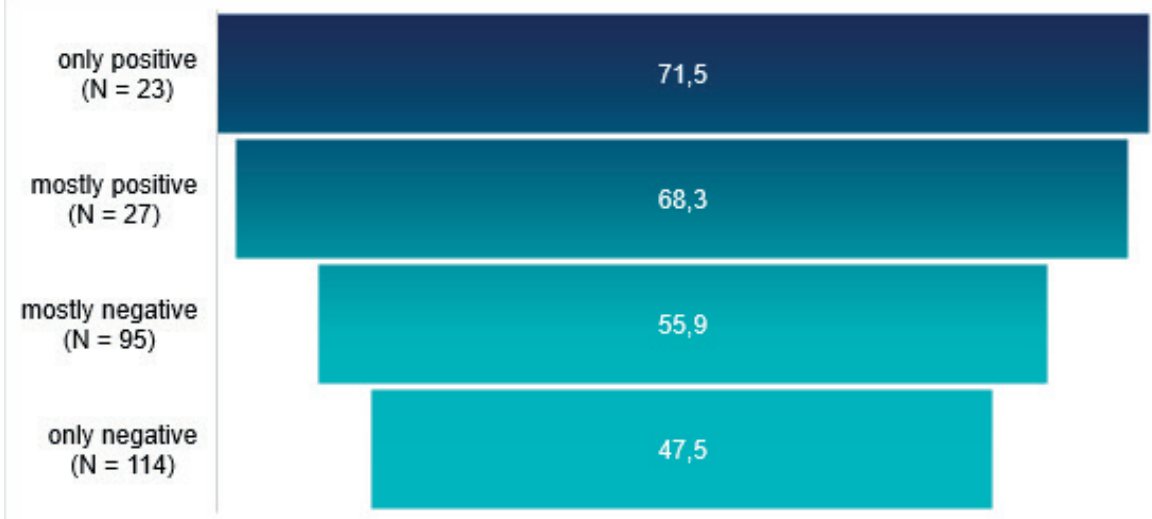

Figure 2. Levels of parental perceived well-being by type of emotions expressed (parents who indicated a number of emotions other than 3 were not included) 
Looking at Figure 2, a significant difference clearly emerges (also confirmed by statistical analysis) in the level of perceived well-being between the group of parents who, when asked to identify three emotions, indicated only - or mostly - positive emotional states and those who, on the other hand, only - or mostly - negative emotions. Even taking into account the numerical inhomogeneity of the groups, there is an evident increase in perceived well-being in correspondence with the increase in positive emotionality, which is also confirmed by the index of direct correlation between positive emotions and well-being ( $\mathrm{r}$ $=.126 ; \mathrm{p}<.05$ ).

Obviously the results do not indicate a causal link between the two variables, nor would they have any reason or usefulness in indicating it: we can only detect an interdependence between the tendency to identify positive emotions in a stressful situation and a good level of individual perceived well-being. However, a sort of virtuous circle seems to emerge: the more parents were able to see some positive aspects during the lockdown, the more they felt positive emotions; feeling positive emotions helps to feel good and a good level of well-being is in turn fundamental to be able to identify resources in a complex situation. This is in line with what was stated about coping skills: success in coping with adverse events, thanks in part to the use of strategies centered on the skills of introspection and reading one's emotional states, has a decisive and positive impact on psychological well-being (Marroquín, Tennen, \& Stanton, 2017).

Our research findings also indicate that well-being positively correlates not only with positive emotions, but also with the perception of being sufficiently equipped to deal with the emergency $(r=.302 ; p<.001)$. We will see in the next section how feeling more or less prepared is also related to perceived emotional states during the emergency.

\section{Emotions and "feeling ready" to face the emergency}

Thinking of yourself as a parent, how ready and equipped did you feel to deal with the current emergency? A query, this one, that we can see as an indirect assessment of one's own parental self-efficacy in handling the various demands associated with the lockdown conditions. A sense of parental self-efficacy refers to the belief that one is able to successfully manage parental functions. As stated by Jones and Prinz (2005) environmental variables or psychological conditions related to an external situation (e.g., pandemic-related stress) may indirectly influence this belief, and this could lead to lower psychological well-being in children (Jones and Prinz, 2005). Indeed, a study of a group of approximately 200 Italian parents conducted by Morelli and colleagues during this pandemic (2020) identified a significant correlation between parental self-efficacy, perceived self-efficacy in managing one's own negative emotions, and their children's emotion regulation skills.

In the group of parents who participated in our research, a fairly high perception of self-efficacy seems to emerge: Figure 3 shows that the majority of parents felt they were definitely ready/equipped to deal with the situation.

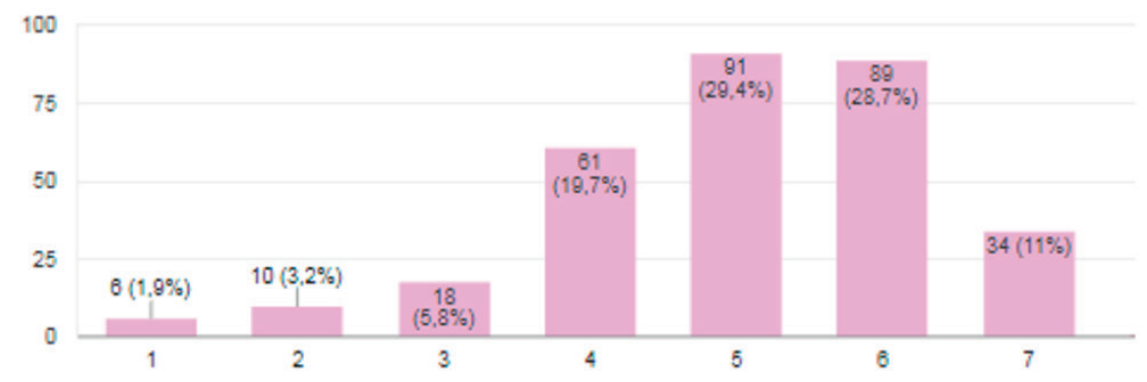

Figure 3. Perception of parental readiness/adequacy in dealing with the emergency (310 valid responses). Thinking about yourself as a parent, how prepared did you feel for the COVID-19 health emergency? (1= not at all equipped, $7=$ fully equipped)

This result is certainly an important and positive indicator of the ability to recognize resources and perceive themselves as able to use them to deal with a complex situation, variables that literature indicates as promoters of well-being in children. Deepening the theme through open-ended questions, the aspects the parents felt more or less prepared emerged: the thematic analysis of the answers, highlighted a fairly "symmetrical" picture. In fact, observing the areas in which parents perceived themselves to have sufficient resources and comparing them with the areas of greater difficulty/shortage of resources, a broad overlap emerges: the parents' responses therefore seem to offer an interesting indicator of the crucial aspects of this emergency situation. The recurring themes concern: reorganization of daily life, listening to and paying attention to children, managing distance learning and managing emotions. Beyond the ability to cope with the "practi-

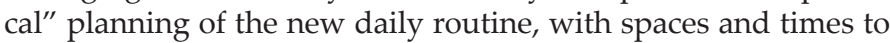
be reshaped, the emotional and relational sphere emerged again as key factors: How to get in touch with your own emotions and those of your children? How to respond to them?
Therefore, it seemed useful to delve further into the analysis by looking in more detail at the two poles of a continuum: those who felt not at all - or almost not at all - prepared to deal with the situation (scores 1 and 2) and those, on the other hand, who felt fully equipped (score 7). What emotions prevailed in these two groups of parents? Analyzing their answers to the question about the three emotions that best represented their state of mind, it emerged that, in the group of parents who felt most distressed, most "short of resources", there was a clear prevalence of negative emotions: $61.5 \%$ of them indicated 3 negative emotions out of 3 , and a further $23.1 \%$ indicated mostly negative emotions; $7.7 \%$ indicated only positive emotions. In the group of parents who felt completely ready, the percentage of those who indicated only negative emotions was $31.3 \%$, half that of the other group; on the other hand, the percentage of parents who named mostly negative emotions was higher (34.4\%). In this group, $12.5 \%$ of parents mentioned positive emotions and $6.3 \%$ mentioned only positive feelings. Beyond the numbers, it appears evident that the feeling of not feeling sufficiently equipped 
to deal with the situation is accompanied by negative moods and - taking up the results of the correlation analysis - also by less perceived well-being. The emotional experience of those who, on the other hand, feel they have more resources at their disposal seems decidedly more varied and - in general - associated with better levels of well-being.

Also in this case, it would not make sense to look for causal links between the variables: it is difficult to say whether those who have a higher level of personal well-being are more able to perceive resources, positive aspects and consequently feel more positive emotions, or - vice versa - those who are more able to see their own resources, are better able to react to situations and therefore "feel better". What undeniably emerges from this survey is the central role of the personal emotional experience when facing an unknown, frightening situation, which is accompanied by the additional pressure to identify resources and be resources for their children. Primarily emotional resources, but how?

Discussion and conclusion: Recognizing resources...what does it mean to be an "emotional coach"?

In the light of the reflections shared so far, it is possible to say that the emotional words of the parents reveal an unequivocal difficulty, linked not only to the fear for their own health and that of their loved ones, but also to the bewilderment of not knowing how to find resources, not knowing what to do or what to say, especially to those who, at that moment, needed reference points most: their children. In fact, children's emerging abilities to understand, express, and regulate their feelings have been attributed to parents' modeling of, responding to, and direct instructing about emotions (Denham, 1998; Denham et al., 2014). But perhaps the question touches even deeper themes: how to get in touch with one's own feelings, even the most frightening ones, without being frightening for those who see in us a resource, a source of security?

In other words, the crucial point seems to be the management of one's own emotions in conditions of high and prolonged exposure to interaction with one's own children. We can hypothesize that much of the fatigue of this constant presence derives precisely from the feeling of being in some way "naked" on an emotional level, and moreover sought after by the gazes of children who - more or less directly - ask for information, reassurance to understand how to cope with this experience.

It is not surprising, then, that the reaction is to cover oneself: many parents have stated that they feel emotionally unprepared precisely because they have not been able to hide their negative emotions, showing security; and many, vice versa, have felt that their ability to simulate calmness was an indicator of their readiness and effectiveness in facing this emergency. These positions seem to echo one of the metaphors used by some of the participants to describe their personal experience of parenting during lockdown: the metaphor of the "Armor". Certainly, the image refers to an idea of protection...but also of hardness, impenetrability. Trying to hide negative emotions, wearing a nice armor polished for the occasion can really be a useful strategy? From this point of view, many studies underlined that negative emotions can impact on a wide range of psychological outcomes throughout the life span, with consequences on several domains (Cavioni et al., 2021; Farina et al, 2021; Kuppens, Realo, \& Diener, 2008; Pallavicini \& Pepe, 2020)

The processes of emotional socialization - as we saw at the beginning of this contribution - are of fundamental importance for children, who through them learn to define, express and give value to their own emotions and to understand those of others (Denham, 1998). Some studies, conducted in particular by Gott- man (Gottman and Declaire, 1997), have identified different parental styles in the approach to emotional experience, which the authors define as true "meta-emotional philosophies" that differ essentially in the degree of awareness, acceptance and management of their own emotions and those of their children. The main styles detected are the dismissing (banning) style and the coaching (guiding) style. In the first case, parents show little emotional awareness and feel afraid of not being able to manage the situation and often have the belief that negative emotions are indicative of poor parenting skills: this leads them to ignore or reject negative emotions or, again, to intervene to change these emotions as quickly as possible. This attitude, while having a protective intentionality, communicates to children the idea that emotions, especially some of them, are not important and that therefore what they feel, and what they are not able to manage, is somehow wrong. Conversely, those with a coaching style are better able to understand, accept and respect emotions, the negative as much as the positive. This attitude leads them to tolerate spending time with an angry, sad or frightened child without being in a hurry to stimulate a change in the intensity and quality of his/her emotion. In this way, situations that provoke negative emotions become opportunities to be close to their children with affection and to face the moment together. Gottman's research group (e.g., Gottman and Declaire, 1997) has found in several studies that children whose parents adopt a coaching style have lower levels of stress, greater emotional competence, and generally better social adjustment.

Giving adequate space to one's emotions without hiding them is therefore also an important meta-communication for children about the real possibility of facing and managing one's feelings. If mom and dad can do it, then so can I!

The words of a mother who took part in the research can perfectly summarize how the real fundamental parental competence is being emotionally present and being accessible to a child, in our imperfection.

"Not being in a hurry, being able to wait not only for events but also for others, being empathetic as much as we can, and being aware that perfection does not exist (even in being a parent and therefore not looking for it in our child either) are the personal resources we think we have.

Instead, I would have liked to have had a little more confidence in my possibilities."

\section{References}

Barari, S., Caria, S., Davola, A., Falco, P., Fetzer, T., Fiorin, S., ... \& Slepoi, F. R. (2020). Evaluating COVID-19 public health messaging in Italy: Self-reported compliance and growing mental health concerns. MedRxiv.

Blakey, S. M., Reuman, L., Jacoby, R. J., \& Abramowitz, J. S. (2015). Tracing "Fearbola": psychological predictors of anxious responding to the threat of ebola. Cognitive Therapy and Research, 39(6), 816-825.

Cavioni, V., Grazzani, I., Ornaghi, V., Agliati, A., \& Pepe, A. (2021). Adolescents' mental health at school: The mediating role of life satisfaction. Frontiers in Psychology, 3322.

Cobham, V. E., McDermott, B., Haslam, D., \& Sanders, M. R. (2016). The role of parents, parenting and the family environment in children's post-disaster mental health. Current Psychiatry Reports, 18(6), 53.

Denham, S. A. (1998). Emotional development in young children. Guilford Press.

Denham, S. A., Mitchell-Copeland, J., Strandberg, K., Auerbach, S., \& Blair, K. (1997). Parental contributions to preschoolers' 
emotional competence: Direct and indirect effects. Motivation and emotion, 21(1), 65-86.

Denham, S. A., Bassett, H. H., Zinsser, K., \& Wyatt, T. M. (2014). How preschoolers' social-emotional learning predicts their early school success: Developing theory-promoting, competency-based assessments. Infant and Child Development, 23(4), 426-454.

Denzin, N. K. (2012). Triangulation 2.0. Journal of mixed methods research, 6(2), 80-88.

Di Giorgio, E., Di Riso, D., Mioni, G., \& Cellini, N. (2020). The interplay between mothers' and children behavioral and psychological factors during COVID-19: an Italian study. European child $\mathcal{E}$ adolescent psychiatry, 1-12.

Dix, T. (1991). The affective organization of parenting: Adaptive and maladaptative processes. Psychological bulletin, 110(1), 3-25.

Emerson, R. W. (2015). Convenience sampling, random sampling, and snowball sampling: How does sampling affect the validity of research?. Journal of Visual Impairment $\mathcal{E}$ Blindness, 109(2), 164-168.

Farina, E., Pepe, A., Ornaghi, V., \& Cavioni, V. (2021). Trait emotional intelligence and school burnout discriminate between high and low alexithymic profiles: a study with female adolescents. Frontiers in Psychology, 12.

Favieri, F., Forte, G., Tambelli, R., \& Casagrande, M. (2021). The Italians in the Time of Coronavirus: Psychosocial Aspects of the Unexpected COVID-19 Pandemic. Frontiers in Psychiatry, 12.

Gottman, J. M., \& Declaire, J. (1997). The heart of parenting: How to raise an emotionally intelligent child. New York, NY: Simon \& Schuster.

Hsieh, H. F., \& Shannon, S. E. (2005). Three approaches to qualitative content analysis. Qualitative health research, 15(9), 12771288.

Holmes, E. A., O'Connor, R. C., Perry, V. H., Tracey, I., Wessely, S., Arseneault, L., ... \& Bullmore, E. (2020). Multidisciplinary research priorities for the COVID-19 pandemic: a call for action for mental health science. The Lancet Psychiatry, 395(10224), 565-574.

Huang, Y., \& Zhao, N. (2020). Generalized anxiety disorder, depressive symptoms and sleep quality during COVID-19 outbreak in China: a web-based cross-sectional survey. Psychiatry research, 288, 112954.

Kurniawan, N. B. (2018, October). A systematic literature review on survey data collection system. In 2018 International Conference on Information Technology Systems and Innovation (ICITSI) (pp. 177-181). IEEE.

Kuppens, P., Realo, A., \& Diener, E. (2008). The role of positive and negative emotions in life satisfaction judgment across nations. Journal of personality and social psychology, 95(1), 66.

Jones, T. L., \& Prinz, R. J. (2005). Potential roles of parental self-efficacy in parent and child adjustment: A review. Clinical psychology review, 25(3), 341-363.

Juth, V., Silver, R. C., Seyle, D. C., Widyatmoko, C. S., \& Tan, E. T. (2015). Post-disaster mental health among parent-child dyads after a major earthquake in Indonesia. Journal of abnormal child psychology, 43(7), 1309-1318.

Lazarus, R. S., \& Folkman, S. (1984). Stress, appraisal, and coping. Springer publishing company.

Leung, G. M., Lam, T. H., Ho, L. M., Ho, S. Y., Chan, B. H. Y., Wong, I. O. L., \& Hedley, A. J. (2003). The impact of community psychological responses on outbreak control for severe acute respiratory syndrome in Hong Kong. Journal of Epidemiology E Community Health, 57(11), 857-863.
Marroquín, B., Tennen, H., \& Stanton, A. L. (2017). Coping, emotion regulation, and well-being: Intrapersonal and interpersonal processes. In The happy mind: Cognitive contributions to well-being (pp. 253-274). Springer, Cham.

Masten, A.S., \& Coatsworth, J.D. (1998). The development of competence in favorable and unfavorable environments: Lessons from research on successful children. American Psychologist, 53, 205-220.

Morelli, M., Cattelino, E., Baiocco, R., Trumello, C., Babore, A., Candelori, C., \& Chirumbolo, A. (2020). Parents and Children During the COVID-19 Lockdown: The Influence of Parenting Distress and Parenting Self-Efficacy on Children's Emotional Well-Being. Frontiers in Psychology, 11, 2584.

Morris A.S., Silk J.S., Steinberg L., Myers S.S., Robinson L.R. (2007). The role of the family context in the development of emotion regulation. Social Development, 16, 361-388.

Pallavicini, F., \& Pepe, A. (2020). Virtual reality games and the role of body involvement in enhancing positive emotions and decreasing anxiety: within-subjects pilot study. JMIR serious games, $8(2)$, e15635.

Pfefferbaum, B., \& North, C. S. (2020). Mental health and the Covid-19 pandemic. New England Journal of Medicine, 383(6), 510-512.

Restubog, S. L. D., Ocampo, A. C. G., \& Wang, L. (2020). Taking control amidst the chaos: Emotion regulation during the COVID-19 pandemic. Journal of Vocational Behavior, 119, 1-6.

Rothe, J., Buse, J., Uhlmann, A., Bluschke, A., \& Roessner, V. (2021). Changes in emotions and worries during the Covid-19 pandemic: an online-survey with children and adults with and without mental health conditions. Child and adolescent psychiatry and mental health, 15(1), 1-9.

Spinelli, M., Lionetti, F., Pastore, M., \& Fasolo, M. (2020). Parents' stress and children's psychological problems in families facing the COVID-19 outbreak in Italy. Frontiers in Psycholo$g y, 11,1713$.

Sprang, G., \& Silman, M. (2013). Posttraumatic stress disorder in parents and youth after health-related disasters. Disaster medicine and public health preparedness, 7(1), 105-110.

Teddlie, C., \& Tashakkori, A. (2006). A general typology of research designs featuring mixed methods. Research in the Schools, 13(1), 12-28.

Uccella, S., De Grandis, E., De Carli, F., D’Apruzzo, M., Siri, L., Preiti, D., ... \& Nobili, L. (2021). Impact of the COVID-19 Outbreak on the Behavior of Families in Italy: A Focus on Children and Adolescents. Frontiers in public health, 9, 32.

Veronese, G., Pepe, A., Massaiu, I., De Mol, A. S., \& Robbins, I. (2017a). Posttraumatic growth is related to subjective well-being of aid workers exposed to cumulative trauma in Palestine. Transcultural Psychiatry, 54(3), 332-356.

Veronese, G., Pepe, A., Dagdouke, J., Addimando, L., \& Yagi, S. (2017b). Measuring well-being in Israel and Palestine: the subjective well-being assessment scale. Psychological reports, 120(6), 1160-1177.

Wang, C., Pan, R., Wan, X., Tan, Y., Xu, L., Ho, C. S., \& Ho, R. C. (2020). Immediate psychological responses and associated factors during the initial stage of the 2019 coronavirus disease (COVID-19) epidemic among the general population in China. International journal of environmental research and public health, 17(5), 1729.

World Health Organization (1998). Info package: mastering depression in primarycare, version 2.2. WHO, Regional Office for Europe. Psychiatric Research Unit,Frederiksborg.T. Krieger et al. / Journal of Affective Disorders 156 (2014) 240244244 
